Proof of Principle experiments that demonstrate utility of cocktail hohlraums for indirect drive ignition

O. S. Jones, J. Schein, M. D. Rosen, L. J. Suter, R. J. Wallace, E. L. Dewald, S. H. Glenzer, K. M. Campbell, J. Gunther, B. A. Hammel, O. L. Landen, C. M. Sorce, R. E. Olsen, G. A. Rochau, H. L. Wilkens, J. L. Kaae, J. D. Kilkenny, A. Nikroo, S. P. Regan

March 14, 2007

Physics of Plasmas 
This document was prepared as an account of work sponsored by an agency of the United States Government. Neither the United States Government nor the University of California nor any of their employees, makes any warranty, express or implied, or assumes any legal liability or responsibility for the accuracy, completeness, or usefulness of any information, apparatus, product, or process disclosed, or represents that its use would not infringe privately owned rights. Reference herein to any specific commercial product, process, or service by trade name, trademark, manufacturer, or otherwise, does not necessarily constitute or imply its endorsement, recommendation, or favoring by the United States Government or the University of California. The views and opinions of authors expressed herein do not necessarily state or reflect those of the United States Government or the University of California, and shall not be used for advertising or product endorsement purposes. 


\title{
Proof of principle experiments that demonstrate utility of cocktail hohlraums for indirect drive ignition
}

\author{
O. S. Jones, J. Schein, M. D. Rosen, L. J. Suter, R. J. Wallace, E. L. Dewald, S. H. \\ Glenzer, K. M. Campbell, J. Gunther, B. A. Hammel, O. L. Landen, C. M. Sorce \\ Lawrence Livermore National Laboratory, 7000 East Avenue, L-399, Livermore, CA \\ R. E. Olson, G. A. Rochau \\ Sandia National Laboratory, Albuquerque, NM \\ H. L. Wilkens, J. L. Kaae, J. D. Kilkenny, A. Nikroo \\ General Atomics, San Diego, CA \\ S. P. Regan \\ Laboratory for Laser Energetics, Rochester, NY
}

\begin{abstract}
This work is a summary of experiments, numerical simulations, and analytic modeling that demonstrate improved radiation confinement when changing from a hohlraum made from gold to one made from a mixture of high $\mathrm{Z}$ materials ("cocktail"). First, the results from several previous planar sample experiments are described that demonstrated the potential of cocktail wall materials. Then a series of more recent experiments are described in which the radiation temperatures of hohlraums made from uranium-based cocktails were directly measured and compared with a gold reference hohlraum. Once cocktail hohlraums with minimal oxygen contamination were made, an increase in radiation of up to $\sim 7 \mathrm{eV}$ was measured, which agrees well with modeling. When applied to an indirectly-driven fusion capsule absorbing $\sim 160 \mathrm{~kJ}$ of $\mathrm{x}$-ray energy,
\end{abstract}


this data suggests that a hohlraum made from a suitably chosen uranium-based cocktail would have about $17 \%$ less wall losses and require about $10 \%$ less laser energy than a gold hohlraum of the same size. 
Increasing the hohlraum coupling efficiency (ratio of capsule absorbed energy to laser energy) for indirectly-driven inertial confinement fusion experiments at the National Ignition Facility (NIF) is desired because it would allow one to drive an ignition capsule with reduced laser energy. The radiation temperature a hohlraum achieves is the result of a balance between sources and sinks (Fig. 1). This radiation energy balance is described by the following equation [1].

$$
E_{\text {cap }}=\left(E_{\text {laser }}-E_{\text {Scatter }}\right) \eta_{C E}-E_{\text {wall }}-E_{L E H}
$$

Here, $\mathrm{E}_{\text {cap }}$ is the x-ray energy absorbed by the fusion capsule in the center of the hohlraum, $\left(\mathrm{E}_{\text {Laser }}-\mathrm{E}_{\text {Scatter }}\right)$ is the laser energy delivered inside the hohlraum with backscatter losses accounted for, $\eta_{C E}$ is the fraction of that energy that is converted to xrays, $E_{\text {wall }}$ is the $\mathrm{x}$-ray energy lost into the hohlraum wall, and $\mathrm{E}_{\mathrm{LEH}}$ is the x-ray energy that escapes out the laser entrance holes (LEHs). In this work, we show that we can reduce $\mathrm{E}_{\mathrm{wall}}$ by replacing a standard gold hohlraum with one made from a combination of high $\mathrm{Z}$ materials. For a fixed $\mathrm{E}_{\text {cap }}$, which is set by the ignition capsule design, reducing the wall losses allows one to reduce the amount of laser energy required for ignition, which increases the lifetime of NIF laser optics and thus has a large impact on facility operating costs. Alternatively, at fixed laser energy, reducing wall losses allows one to drive a capsule with more absorbed energy, thus increasing margin for ignition.

The $\mathrm{x}$-ray losses into the hohlraum wall are well modeled as a radiation ablation front diffusing into a cold wall, the so-called Marshak wave [2]. The starting point for that theory is the one-dimensional diffusion equation that describes the conservation of energy for a radiating fluid. In words, that equation states that the time derivative of the energy density is equal to the gradient of the diffusive energy flux. If we neglect the 
radiation component of the energy density and the material component of the diffusive energy flux, we get

$\frac{\partial}{\partial t}(\rho e)=\frac{\partial}{\partial x}\left(\frac{c \lambda_{R}}{3} \frac{\partial}{\partial x}\left(a T^{4}\right)\right)$

where $\rho$ is the density, e is the specific heat, $\lambda_{R}$ is the Rosseland mean free path (or optical depth), and $\mathrm{T}$ is the material temperature. But $\lambda_{\mathrm{R}}=1 /(\rho \kappa)$, where $\kappa$ is the Rosseland mean opacity, so substituting this and combining terms, we can rewrite Eq (2) as

$\frac{\partial}{\partial t}(\rho e)=\frac{\partial}{\partial x}\left(\frac{4}{3 \kappa \rho} \frac{\partial}{\partial x}\left(\sigma T^{4}\right)\right)$

where $\sigma$ is the Stephan-Boltzmann constant. If a temperature source is applied at a boundary, the solution to this equation is a steep nonlinear heat front that diffuses into the wall, as shown in Figure 2. The steepness of the front comes from the fact that the flux varies as $\mathrm{T}^{4}$ and also because of the strong temperature dependence of the opacity. Since the front is steep, we can approximate the actual temperature profile as a flat temperature profile at the boundary temperature, $\mathrm{T}(\mathrm{t})$, up to a depth, $\mathrm{X}_{\mathrm{F}}$, where the temperature drops sharply to the cold material temperature. This simplification allows us to use simple dimensional analysis to get the basic scaling of the mass per unit area of heated material, $\mathrm{m}_{\mathrm{F}}$, as a function of $\mathrm{T}$, $\mathrm{t}$, and material properties. Simply substitute $1 / \mathrm{t}$ for each time derivative and $1 / \mathrm{X}_{\mathrm{F}}$ for each spatial derivative in $\mathrm{Eq}$ (3) and rearrange to get

$$
m_{F}=\rho X_{F} \sim \sqrt{\frac{T^{4} t}{\kappa e}}
$$

To formulate an expression for the heated mass that applies to gold, we relate $\kappa$ and e to $\rho$ and $\mathrm{T}$ via the following power law fits. 
$\kappa=\kappa_{o} \frac{\rho^{0.2}}{T^{1.6}}$

$e=e_{o} \frac{T^{1.6}}{\rho^{0.14}}$

Then, using these power law fits with Hammer and Rosen's similarity solutions for a subsonic heat front $[3,4]$ wherein $\rho \sim \mathrm{m}_{\mathrm{F}} / \mathrm{c}_{\mathrm{s}} \mathrm{t}$, where $\mathrm{c}_{\mathrm{s}}$ is the sound speed in the heated material, we can show that the heated mass per area scales like

$m_{F} \sim \frac{T^{1.91} t^{0.52}}{\left(\kappa_{o} e_{o}\right)^{0.48}}$

From the product of Eqs (6) and (7) we find that the wall loss per area for a gold wall exposed to a temperature radiation source for a time $t$ is given by

$$
E_{\text {wall }} / A_{\text {wall }} \sim\left(e_{0}^{0.7} / \kappa_{0}^{0.4}\right) T^{3.3}(t) \cdot t^{0.59}
$$

This shows that in order to reduce the wall loss, we need a wall material that has both low specific heat $(\varepsilon)$ and high opacity $(\kappa)[4,5]$. Since the radiation energy is conserved, whatever does not go into heating the wall material must be re-emitted back into the hohlraum (that is, the temperature profile will adjust itself in accordance with the opacity of the heated material to let the right amount of energy back out). The emphasis on specific heat is of particular importance in this work. To date the predominant focus of the field has been on opacity.

\section{Early work and application to NIF}

It has long been known that suitably chosen mixtures of materials ("cocktails") having overlapping energy bands should have a higher opacity than any single material. For example, Figure 3 shows the frequency-dependent cold opacities for gold and 
gadolinium. For a pure gold wall, radiation would tend to leak out preferentially through the low spots in the frequency-dependent opacity. But the peaks and valleys of the opacity curve for gadolinium are shifted in frequency relative to gold's in a way that the materials fill in each other's gaps in opacity. This strategy was suggested for use in enhancing x-ray conversion efficiency [6], and, most relevant to this work, in reducing wall loss [7].

Colombant, et al. [8] performed a numerical study using the STA opacity model [9] in which they found various combinations of materials having higher Rosseland mean opacities than gold at $250 \mathrm{eV}$ and $1 \mathrm{~g} / \mathrm{cc}$. Suter [10] later did a series of calculations in which he analyzed many combinations of materials in order to find ones that minimized wall losses for a shaped radiation drive having a $250 \mathrm{eV}$ peak drive temperature. These were Lasnex calculations [11] in which a Planckian radiation source was applied at the boundary of a one-dimensional slab of material. He found that the mixtures with the lowest wall losses invariably included uranium, because as Eq (8) implies, that kept the average $\mathrm{Z}$ of the mixture high, thus minimizing the heat capacity. We redid this analysis for a generic NIF ignition drive having a $300 \mathrm{eV}$ peak drive temperature and found that a combination of $60 \% \mathrm{U}, 20 \% \mathrm{Dy}$, and $20 \% \mathrm{Au}$ (atom \%) minimized the wall losses. Figure 4 shows the wall loss of several different mixtures relative to that of pure gold as a function of the fraction of gold in the cocktail. The black curve is for a uranium-gold mixture and shows that uranium has less loss than gold, and that a cocktail of $25 \%$ gold and $75 \%$ uranium has lower losses than either pure material. The red curve is for a threecomponent mixture of uranium-gold-dysprosium. We find that the optimum mixture has $20 \%$ gold, $20 \%$ dysprosium, and $60 \%$ uranium. 
The minimum wall loss material depends on the detailed shape of the radiation drive, especially the final rise and peak drive, because that is where most of the drive energy resides. It turns out that uranium and mixtures with uranium in them do better in comparison with gold as the temperature is increased. Figure 5 is a plot of the Rosseland mean opacity of the $\mathrm{U}_{66} \mathrm{Au}_{2} \mathrm{Dy}_{.2}$ cocktail and that of gold as a function of temperature. Note that at $150 \mathrm{eV}$ the opacity of the gold and cocktail are about the same. The reason is that near $100 \mathrm{eV}$ gold has several $\mathrm{n}=4$ to $\mathrm{n}=4$ transitions that fill in holes in the opacity at energies near the peak of the Rosseland mean opacity weighting function. One important consequence of this scaling is that subscale tests to demonstrate the advantage of this cocktail must be done at temperatures sufficiently above $150 \mathrm{eV}$ to get a measurable effect.

To quantify the energetic benefit of cocktails to NIF, we applied the specific radiation drive shape shown in Figure 6 (left axis) to the $\mathrm{U}_{.6} \mathrm{Au}_{.2} \mathrm{Dy}_{.2}$ cocktail. This drive corresponds to a particular 0.2-mm diameter $300 \mathrm{eV} \mathrm{Cu}$-doped Be capsule design that absorbs about $160 \mathrm{~kJ}$ of x-ray energy [12]. Figure 6 also shows that the calculated (using Lasnex with STA opacities) time-dependent ratio of the wall loss of the cocktail to that of gold is 0.825 by the end of the pulse (17.5\% reduction in wall loss). We also calculate that a gold hohlraum approximately $0.5 \mathrm{~mm}$ in diameter and $0.9 \mathrm{~m} \mathrm{~mm}$ long would require about $1.1 \mathrm{MJ}$ of laser energy to drive this capsule. This assumes $10 \%$ extra energy to account for any laser backscatter and assumes an x-ray conversion efficiency of 0.82 . The x-ray energy accounting for the gold hohlraum is shown in Fig. 7. If we replace the gold with the U:Au:Dy cocktail, this results in about 10\% savings in laser energy, so that the same capsule now requires 1 MJ of laser energy (see Fig. 7). Reducing the required 
laser energy by $10 \%$ is beneficial because it reduces the stress on the laser optics, thus increasing optics life.

\section{Promising planar sample experiments}

We will now discuss in some detail two experiments that appeared to demonstrate the promise of cocktails. The first was an experiment by Orzechowski, et al. [7] in which they measured the burn-through time of side-by-side foils made of gold and gold/gadolinium $(\mathrm{Au} / \mathrm{Gd})$. The $\mathrm{Au} / \mathrm{Gd}$ foil consisted of alternating thin layers of each material. The foils were placed over a hole in the side of a NOVA laser heated hohlraum (Figure 8). Recall from Eq (7) that the areal mass heated by the Marshak front is given approximately by

$$
m_{F} \approx m_{o} \frac{T(t)^{2} t^{0.5}}{\left(\kappa_{o} e_{o}\right)^{0.5}}
$$

where $\mathrm{m}_{\mathrm{o}}$ is some constant. We assume that the temperature varies with time as $T=T_{o} t^{0.2}$, which is a good approximation for a hohlraum heated by a constant power laser, and substitute that into Eq (9). Setting the heated areal mass $\left(\mathrm{m}_{\mathrm{F}}\right)$ equal to the sample areal mass $\left(\mathrm{m}_{\mathrm{s}}\right)$ and solving for time, we get the following expression for the burn-through time

$t_{b t} \approx \frac{m_{s}}{m_{o}} \frac{1}{T_{o}^{2}} \sqrt{\kappa_{o} e_{o}}$.

Since the areal masses for the two foils were the same, it was expected that the $\mathrm{Au} / \mathrm{Gd}$ foil would burn through later due to its higher opacity. A delay was observed, as shown in Figure 8, and it agreed with their estimates based on the XSN average atom model [13]. 
Burn-through time is not directly related to the wall loss, as can be seen by its scaling with $\mathrm{e}_{0}$. An increase in $\mathrm{e}_{0}$, which actually increases the wall loss, would also increase the burn-through time. To get at the wall loss more directly, we decided to compare the reemission (albedo) of cocktail to gold. The albedo is defined as the ratio of the re-emitted flux to the incident flux, and the re-emitted flux is just the incident minus the absorbed flux (wall loss), so the albedo at a specified $\mathrm{T}$ and time will go as

$$
\frac{F_{r e-e m i t}}{\sigma T^{4}}=1-\frac{F_{\text {wall }}}{\sigma T^{4}} \sim 1-C \frac{e_{o}^{0.7}}{\kappa_{o}^{0.4}} .
$$

The scaling shows that an increase in albedo implies a decrease in the wall loss. The relative cocktail albedo was measured in side-by-side re-emission in experiments that were done on the Omega laser [14] in 2000 and 2001. The experiments (Fig. 9) consisted of a gold half hohlraum ("halfraum") heated by 15 beams. The inside backwall of the halfraum was a 25 micron thick gold disk, half of which was coated with several microns of $\mathrm{U}_{4} \mathrm{Au}_{.2} \mathrm{Dy}_{.2} \mathrm{Ta}_{2}$ cocktail. The cocktail was made by co-sputtering from a heterogenous source made from a block of uranium with plugs of the other elements interspersed in such a way as to give the correct ratio of elements at the target. This was actually the optimum cocktail that came out of an earlier iteration [15] of Suter's NIF wall loss study [10]. The split gold/cocktail disk was viewed down the halfraum axis through the LEH with a filtered soft $\mathrm{x}$-ray imager. This instrument produces images at four times during the experiment for each of three filters. Broadband filters centered at $260 \mathrm{eV}, 450 \mathrm{eV}$, $760 \mathrm{eV}$, and $>2.5 \mathrm{keV}$ were used during the course of this experimental series, but only the $450 \mathrm{eV}$ channel was used for all the halfraum sizes tested. The filter response function for the $450 \mathrm{eV}$ channel is also shown in Figure 9. 
A soft x-ray image filtered at $450 \mathrm{eV}$ from one particular shot is shown in Figure 10. This was a 3-mm-diameter halfraum that reach a peak $\mathrm{T}$ of about $100 \mathrm{eV}$. In the experimental images the gold is on the bottom and the cocktail is on the top. From a vertical lineout of the emission image we see that in this case the cocktail material actually emitted less than the gold (as predicted for the similar $\mathrm{U}_{.6} \mathrm{Au}_{.2} \mathrm{Dy}{ }_{.2}$ cocktail, Fig. 5). In contrast, a $450 \mathrm{eV}$ image and corresponding lineout for a 1-mm-diameter halfraum that reached a peak $\mathrm{T}$ of $260 \mathrm{eV}$ is shown in Figure 11, and at this temperature the cocktail emitted more strongly (implying less wall loss). Figure 12 is a summary of all the experiments in this series. The peak $\mathrm{T}$ of these halfraums was varied from $100 \mathrm{eV}$ to $260 \mathrm{eV}$ by varying the halfraum diameter from $3 \mathrm{~mm}$ to $1 \mathrm{~mm}$. We calculated the expected emission ratio at the time of the best image from each experiment by comparing the filtered emission from 1D Lasnex calculations using STA opacities and a frequency-dependent radiation source extracted from separate $2 \mathrm{D}$ hohlraums calculations. The predicted temperature dependence of the cocktail to gold emission ratio for the $450 \mathrm{eV}$ channel agreed well with the measurements.

\section{First hohlraum experiments}

Because these planar sample experiments seemed to indicate that the various cocktail materials that had been tested were performing as expected, we proceeded to the next logical step, which was to measure the radiation temperature of a cocktail hohlraum in an integrated experiment and compare with a comparable gold hohlraum. These integrated hohlraum experiments were performed at the Omega Laser Facility. The experiment setup is shown in Figure 13. The hohlraums $2.06 \mathrm{~mm}$ in length, with a diameter of 1.2 
$\mathrm{mm}$. The LEH diameter was $0.8 \mathrm{~mm}$. They were heated with a $1 \mathrm{~ns}$ laser pulse (40 beams, $\sim 19 \mathrm{~kJ}$, see Fig. 13) and were predicted to have a peak $\mathrm{T}$ of $\sim 270 \mathrm{eV}$ (for gold). Two different cocktail mixtures were used. The first experiments used the four-element $\mathrm{U}_{4} \mathrm{Au}_{2} \mathrm{Dy}_{22} \mathrm{Ta}_{.2}$ cocktail that was also used for the previously described split-disk reemission experiments. Subsequent experiments used the three-element $\mathrm{U}_{4} \mathrm{Au}_{.2} \mathrm{Dy}{ }_{.2}$ cocktail that calculated to have slightly lower wall losses than the four-element cocktail. As in the split-disk re-emission experiments, these were co-sputtered cocktails. In this case, they were co-sputtered onto a mandrel that was then chemically leached away. Some of the cocktail hohlraums had a gold liner of $0.1-0.2$ microns on the inside with the idea being that most or all of the x-ray conversion would occur in the gold liner (removing x-ray conversion efficiency as a variable in those experiments). Note that all the cocktails contained $\mathrm{U}$ alloyed with $\mathrm{Nb}$ (rather than pure $\mathrm{U}$ ), because that was readily available. The inclusion of this amount of $\mathrm{Nb}$ results in a slight degradation of the cocktail performance, which was accounted for in our modeling.

The radiation temperature was inferred from a time-resolved measurement of the radiation flux out of the LEH using a broadband 10 channel soft x-ray spectrometer ("Dante") [16] over an energy range from $0-5 \mathrm{keV}$. The radiation power per solid angle was obtained by convolving a trial spectrum with the channel response functions to get computed channel signals and then iterating the spectrum until the computed signals approximately matched the measured signals for each channel. We define the radiation temperature as the spectrally integrated flux divided by the effective $x$-ray source size given by the LEH size as viewed from the Dante line of sight (37.4 degrees relative to hohlraum axis). That is 
$T=\left[\frac{F_{\text {Dante }} \pi}{\sigma A_{L E H} \cos \theta}\right]^{1 / 4}$

The source size was measured with a filtered soft $x$-ray framing camera. The backscattered laser energy due to Brillouin (SBS) and Raman (SRS) Scattering was measured on two beams using the full aperture backscatter station.

In this work, the key measurement is the difference in flux between the cocktail and gold hohlraums, so it is the relative error in the measurement that is important. Since the fluxes we are measuring are close to each other in absolute magnitude, the systematic errors in the Dante diode calibrations largely cancel out. The shot-to-shot noise in the diode signals is small compared with other errors, so the remaining sources of error in this measurement are due to uncertainties in the source size, the hohlraum size, the total laser power and energy, the laser power and energy of the beams directly viewed by Dante, and the backscattered energy.

To estimate these errors, we introduce a simple energy balance model for a gold hohlraum. We start from the energy balance Eq (1) modified to account for the fact that these hohlraums did not contain a capsule.

$\left(E_{\text {laser }}-E_{\text {Scatter }}\right) \eta_{C E}=E_{\text {wall }}+E_{L E H}$

Assuming that the radiation temperature for the $1 \mathrm{~ns}$ Omega experiments rises with $\mathrm{T}$ $\sim \mathrm{t}^{0.18}$, which is consistent with our measurements, the wall loss (in MJ) for a gold hohlraum is [4]

$E_{\text {wall } \_ \text {Au }}=A_{\text {wall }} \cdot 0.39 \cdot T_{0}^{3.3} \cdot t^{1.18}$

where $T_{o}$ is the peak radiation temperature (in heV) at $1 \mathrm{~ns}, \mathrm{~A}_{\text {wall }}$ is the hohlraum wall area is in $\mathrm{mm}^{2}$, and $\mathrm{t}$ is time in $\mathrm{ns}$. The losses out the LEH are 
$E_{L E H}=A_{L E H} \cdot 0.58 \cdot T_{0}^{4} \cdot t^{1.72}$

The conversion efficiency in this model is

$\eta=0.85 t^{0.2}$

Solving equations (13)-(16) yields a $\mathrm{T}(\mathrm{t})$ that agrees reasonably well with our gold hohlraum data. With this model, we find that the estimated uncertainties in wall area (2\%), LEH area (2\%), and absorbed (backscatter subtracted) laser energy (2\%) yield an estimated error in the relative flux measurement of $3.2 \%$. The additional uncertainty due to a $3 \%$ shot-to-shot variation in the total brightness of the laser spots visible in the Dante field of view is estimated to be an additional $1 \%$. Thus the total expected error in the relative flux measurement is $3.3 \%(0.83 \%$ in $\mathrm{T})$.

We used a simple energy balance semi-analytical model and more detailed integrated Lasnex simulations of the experiment to compare against the measurements. For the simple model we use Eqs (13)-(16) to get $\operatorname{Tr}(\mathrm{t})$ for the gold and then use that as a source for high-resolution one-dimensional Lasnex calculations of cocktail and gold slabs to find the wall loss for each material. We then take the time-dependent ratio of the cocktail wall loss to the gold wall loss, multiply Eq (14) by that factor, and then solve for the cocktail $\mathrm{T}(\mathrm{t})$. Note that we make the implicit assumption that the $\mathrm{x}$-ray conversion efficiency is the same for both types of hohlraums in these experiments.

For the Lasnex calculations we model the entire problem in an axially symmetric computational grid, including the laser deposition, conversion to x-rays, and x-ray losses. This allows us to use the measured laser power and source size for each simulation. The temperature is obtained from the LEH flux (as in the experiment) by post-processing the simulation results from the Dante view angle. Figure 14 shows a material plot at $1 \mathrm{~ns}$ for 
a typical Lasnex 2D calculation of one of the experiments. This one had a 0.2 -micron $\mathrm{Au}$ liner and it is evident from the laser rays that the laser does not ablate through the $\mathrm{Au}$ liner in this case.

For the $\mathrm{U}(\mathrm{Nb})$ :Au:Dy:Ta cocktail hohlraum with no gold liner, the models predicted about a $10 \%$ increase in the total radiation flux for the cocktails compared to gold. Figure 15 shows the measured flux versus time for 2 gold shots (solid red) and 3 cocktail shots (dashed blue). The results were surprising because the total flux from the cocktail hohlraums was actually lower on average than for the gold. However, the inferred total laser backscattered energy (especially SRS) was higher for the cocktails (about $10 \%$ as compared to $7 \%$ for the gold) and there was some variation in the laser energy for these shots. Even when data were normalized to the same absorbed laser energy using Eqs 1316 , the expected increase in radiation temperature (or flux) was not observed.

Further experiments were done with the $\mathrm{U}(\mathrm{Nb})$ :Au:Dy cocktail mixture. For these experiments two refinements were made. The inside of the cocktail material was lined with a 0.1 micron Au layer so that the gold and gold-lined cocktail hohlraums would be forced to have the same x-ray conversion. Also, the end caps of the gold and cocktail hohlraums were replaced with separate flat gold washers so that any uncertainty in the result due to differences in LEH closure could be eliminated. These changes also lowered the expected increase in $\mathrm{T}$ by adding gold to the cocktail hohlraum. Figure 16 is a summary of the data from all of these experiments compared to theoretical predictions (from the simple energy balance model). The data are plotted in terms of the increase in the peak $\Delta \mathrm{T}_{\mathrm{r}}$, which is defined as the peak $\mathrm{T}$ inferred from Dante (Eq 12) for each cocktail shot subtracted by the peak baseline gold temperature. The baseline gold 
temperature was an average of 2-3 gold shots taken on the same day as a given cocktail data point. All the data was normalized to the same absorbed laser energy using the measured laser energy and backscattered energy for each shot. Although a peak increase in $\mathrm{T}$ of 5.5 to $7 \mathrm{eV}$ was predicted (black bars), the measured increases were in the range of 0 to $4 \mathrm{eV}$.

\section{Oxygen hypothesis}

A hypothesis that the cocktails contained oxygen emerged from our efforts to understand this discrepancy. We know from $\mathrm{Eq}(8)$ that wall loss scales as $\mathrm{e}_{\mathrm{o}}^{0.7}$. The specific heat scales as approximately as $Z_{B} / A$, where $Z_{B}$ is the average ionization state and $A$ is the atomic weight. For $\mathrm{Au}$ or $\mathrm{U}$ at $200-300 \mathrm{eV} \mathrm{Z}$ B $/ \mathrm{A}$ is about $1 / 4$, whereas for oxygen it is about $1 / 2$ because it is fully ionized. So, mixing in a large amount of oxygen could substantially increase the specific heat of the cocktail mixture.

Up to this point the cocktail hohlraums had been made by co-sputtering the cocktail mixture onto a rotating aluminum mandrel and then leaching away the mandrel with a $\mathrm{NaOH}$ solution. Since U and Dy both have a tendency to bond with oxygen, there was a concern that oxygen could attach itself to the cocktail during this step. If we assume that each $\mathrm{U}$ and Dy bonds with an $\mathrm{O}$ to make a $(\mathrm{UO}){ }_{.6} \mathrm{Au}_{.2}(\mathrm{DyO})_{.2}$ cocktail $(42 \% \mathrm{O})$, then we find that the specific heat at $250 \mathrm{eV}$ and $1 \mathrm{~g} / \mathrm{cc}$ is increased by $\sim 9 \%$, while the opacity is slightly reduced. From the wall loss scaling we know this will lead to larger wall losses and in fact both the energy balance model and 2D Lasnex predict a smaller maximum increase in the peak $\Delta \mathrm{T}_{\mathrm{r}}$ of 3.2 to $3.7 \mathrm{eV}$ (see green bars in Figure 16), which is closer to the data. 
There is another experiment that also bolstered the oxygen hypothesis. Olson, et al. [17] simultaneously measured the burn-through and re-emission of side-by-side Au and $\mathrm{Au}: \mathrm{Dy}: \mathrm{Nd}$ foils and found that although the burn-through data could be consistent with higher cocktail opacity, there was no evidence of higher cocktail re-emission, implying no reduction in wall loss. These were multi-layer foils (like the Orzechowski Au:Gd foils, sec. II). At the time they reported that they detected some (unquantified) amount of oxygen contamination in the Dy and Nd layers. They took measures to reduce the amount of oxygen by adding a gold overcoat, but this did not change their results [18]. We now know these foils had about $40 \%$ oxygen [19]. From the expression for ablated mass (Eq 7) and assuming $T(t) \sim T_{0} t^{1}$, we find that

$\kappa_{o} e_{o} \sim \frac{t_{b t}^{1.5}}{(\rho \Delta x)^{2.08}}$

where $\rho \Delta x$ is the sample areal density. Substituting the experimental values from [17] into Eq 17 and taking the ratio of the $\mathrm{Au}: \mathrm{Dy}: \mathrm{Nd}$ cocktail to that of gold, we find $\frac{\left(\kappa_{o} e_{o}\right)_{A u: D y: N d}}{\left(\kappa_{o} e_{o}\right)_{A u}}=\left[\frac{1.9}{1.5}\right]^{2.08}\left[\frac{1.3}{1.45}\right]^{1.5}=1.38$

For Au:Dy:Nd and $\mathrm{Au}$ at $160 \mathrm{eV}$ and $1 \mathrm{~g} / \mathrm{cc}$, the ratio of opacities (cocktail over gold) is 1.14 and the ratio of specific heats is 1.07 , so the ratio of their product is 1.22 . However, when $40 \%$ atomic fraction of oxygen is added to the cocktail, the opacity ratio is 1.13 , the specific heat ratio is 1.20 , and the product is 1.36 , which is in better agreement with the data. In addition, recall from Eq (7) that $1-\alpha$ scales as $\mathrm{e}_{\mathrm{o}}{ }^{7} / \mathrm{\kappa}{ }^{-4}$. The ratio (cocktail over gold) of that expression is 0.99 without oxygen and 1.08 with oxygen. Thus the addition of oxygen would lead to the cocktail having a lower albedo than the gold, which is also consistent with their measurements. 
It might seem that the split-disk re-emission results (sec. II) contradict the oxygen hypothesis, because those cocktails had higher re-emission than gold above $200 \mathrm{eV}$, whereas hohlraums made from the same materials did not work. However, there is a key difference. Unlike the hohlraums and the foils, there was no chemical leaching step involved in making the split disks (the cocktail was simply sputtered onto a gold disk). Thus, although the oxygen levels were not measured for those experiments, it seems likely (given their measured re-emission) that they did not have enough oxygen in them to noticeably change their properties.

\section{Experiments with new low-oxygen cocktail hohlraums}

So, for the next series of experiments the amount of oxygen in the cocktail coating material was controlled using a different hohlraum manufacturing process. The new process, illustrated in Figure 17, employs a gold substrate hohlraum split in two along the hohlraum axis producing two shaped halves (Fig. 17a). A total of $5 \mu \mathrm{m}$ of cocktail material is co-sputtered onto the inside surface of the halves. The cocktail is then overcoated with $0.2 \mu \mathrm{m} \mathrm{Au} \mathrm{liner.} \mathrm{This} \mathrm{Au} \mathrm{liner} \mathrm{serves} \mathrm{to} \mathrm{prevent} \mathrm{oxygen} \mathrm{from} \mathrm{getting} \mathrm{to} \mathrm{the}$ cocktail material. The two halves are then joined (Fig. 17b) to form the hohlraum (the gold hohlraums are also constructed this way). All hohlraums used had a wall thickness of $100 \mu \mathrm{m}$ for additional mechanical stability and a constant LEH area/wall area ratio of $11 \%$. The finished hohlraums were stored in nitrogen filled containers until one hour before each experiment. Calibrated flat witness plates were coated at the same time as the hohlraum halves. The witness plates were analyzed using Auger spectroscopy in order to verify that the correct percentage of each element was present and to measure the amount 
of oxygen present. We found that there was a thin ( 0.1 micron) layer directly underneath the $0.2 \mu \mathrm{m}$ protective Au layer that contained $5-10 \%$ oxygen, and that deeper into the cocktail there was no detectable oxygen (Figure 18). This amount of oxygen remained stable for weeks in a controlled nitrogen atmosphere, and is predicted to have a negligible influence on the wall loss.

Figure 19 shows the measured time history of the measured total (spectrally-integrated) radiation flux for two sequential experiments (one cocktail, one gold) using the new type of cocktail hohlraum. The total laser energy for these shots ranges from $19.18 \mathrm{~kJ}$ to 19.45 $\mathrm{kJ}$, the energy for the beams viewed by Dante varied by $\sim 3 \%$, and the backscatter varies from $3-4 \%$. After initially applying the laser pulse, the inferred radiation temperature increases in $\sim 300 \mathrm{ps}$ to a value of $230 \mathrm{eV}$. Afterwards it continues to increase more slowly with time $\left(\sim \mathfrak{t}^{0.18}\right)$ as assumed in the analytic estimates. The cocktail flux begins to rise above the gold flux at about 0.4 ns. By the peak of the pulse, the inferred cocktail temperatures are 5-6 eV above the gold, which is a difference that exceeds the relative error bars. The Dante spectrum at the peak of the drive (Figure 20) indicates that the cocktail is more advantageous below $2 \mathrm{keV}$, where most of the drive energy resides. We also post-processed the output from the 2D Lasnex simulations using the Dante channel response functions in order to get simulated Dante channel signals. We then form a ratio of the cocktail to gold signal for each channel, which we can then compare to the same ratio for the actual measurement. The calculated to measured ratio is shown for each Dante channel in Figure 21 and seen to be within 5\% for all channels. The flux above 3 $\mathrm{keV}$ was analyzed by time integrated spectroscopy and it was found that while in the case of $\mathrm{Au}$ the radiation is mainly produced by Au M-band emission on top of the black body 
continuum the Cocktails show mostly $\mathrm{U}$ and Dy specific transitions above $3.5 \mathrm{keV}$, with weaker $\mathrm{Au}$ lines as expected. The source size was monitored using the soft $\mathrm{x}$-ray imager with 50 ps temporal resolution and we saw no appreciable LEH closure.

The results from Figure 19 are re-plotted in Figure 22 in terms of $\Delta T_{r}$ and compared to our model predictions. The measured time-dependent increase in $\mathrm{T}$ agrees quite well with theory. The time-dependence is due to two factors. Until the Marshak wave has ablated past the 0.2 micron gold coating, we expect no difference. Also, from analytical scaling laws [4], we expect the cocktail wall loss to gold wall loss to scale as $\mathrm{T}^{-0.2}$, so as the temperature rises during the experiment, the relative advantage of the cocktail keeps increasing.

To investigate the temperature scaling of the cocktail mixture, we did some experiments with the same size hohlraums, but only $5000 \mathrm{~J}$ of laser energy. These had an expected $\mathrm{T}$ of about $180 \mathrm{eV}$. To reach temperatures higher than $270 \mathrm{eV}$, we also used smaller hohlraums that were $1.0 \mathrm{~mm}$ diameter, $1.75 \mathrm{~mm}$ long, had $0.67 \mathrm{~mm}$ diameter LEHs, and reached a peak $\mathrm{T}$ of $305 \mathrm{eV}$ when heated by $19.5 \mathrm{~kJ}$. We analyzed the $180 \mathrm{eV}$ and $305 \mathrm{eV}$ (nominal peak gold T) hohlraums in the same way as the $270 \mathrm{eV}$ hohlraums above. From Lasnex the calculated cocktail to gold wall loss ratio at $1 \mathrm{~ns}$ is $96.7 \%$ for $180 \mathrm{eV}, 88.6 \%$ for $270 \mathrm{eV}$, and $86.1 \%$ for $305 \mathrm{eV}$ (confirming the analytical $\mathrm{T}^{-0.2}$ scaling). Even at the highest temperature the reduction in wall loss energy is lower than for NIF because of the relatively larger role of rise time and gold layer overcoat thickness in the shorter duration Omega experiments. Figure 23 shows the difference in $\mathrm{T}$ at the peak of the drive for all the experiments as a function of the nominal peak gold radiation temperature. The experimental results of this campaign show an increase in $\mathrm{T}$ of $1 \mathrm{eV}$ to $7 \mathrm{eV}$ as the 
hohlraum peak $\mathrm{T}$ is varied, which is in agreement with semi-analytical (red line) and Lasnex 2D (blue circles) predictions for Au-lined cocktail hohlraums. Each data point represents the increase in peak $\mathrm{T}$ for each cocktail tested relative to the average peak $\mathrm{T}$ of two corresponding gold (control) hohlraums. To remove the effects of the small shot-toshot variations in absorbed laser energy, the data at each $\mathrm{T}$ were normalized to the same absorbed laser energy using Eqs (13-16).

Looking to the future, cocktail hohlraums are now planned for use in NIF ignition experiments. There is a development effort underway at General Atomics to make NIFscale hohlraums. These hohlraums are being built using a multilayer technique rather than a co-sputter technique, and are required to have low oxygen content. They are using the $\mathrm{U}_{.75} \mathrm{Au}_{25}$ mixture shown in Figure 4. Figure 24 is a photo of an early prototype of a $5.1 \mathrm{~mm}$ diameter (NIF-scale) hohlraum half with a 7-micron thick cocktail layer and 0.2micron $\mathrm{Au}$ overcoat. Preliminary experiments have already been done to test the properties of foils made from the NIF multilayer cocktail [19]. These experiments measured the burn-through and re-emission on Omega using an experimental geometry similar to Olson [17].

In summary we presented experiments demonstrating up to a $7 \mathrm{eV}$ increase in radiation temperature for U:Au:Dy cocktail hohlraums compared to similarly constructed gold hohlraums. This increase and its scaling with peak temperature agree very well with a semi-analytic model and integrated Lasnex calculations, showing that the increase is attributable to a reduction in the $\mathrm{x}$-ray wall losses. This proof of principle experiment gives us confidence in ignition target design calculations that predict the U:Au:Dy cocktail will reduce wall losses compare to gold by $17 \%$, saving $10 \%$ in laser energy. 
The authors wish to acknowledge the help and outstanding performance of the Omega team at the University of Rochester, the Physics Dept. of LLNL for providing opacity and EOS data, and the computational support of the LLNL LASNEX team.

This work was performed under the auspices of the U.S. Department of Energy by the

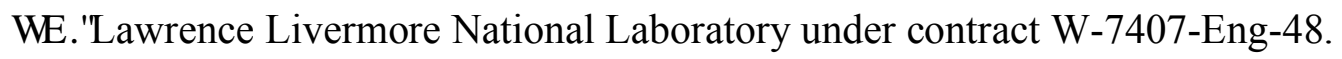

[1] J. D. Lindl, Phys. Plasmas 2, 3933 (1995); J. D. Lindl

et al., Phys. Plasmas 11, 339 (2004).

[2] R. E. Marshak, Phys. Fluids, 1, 24 (1958)

[3] J. H. Hammer and M. D. Rosen, Phys. Plasmas 10, 1829 (2003)

[4] M. D. Rosen, "Proc. of the Scottish Univ. Summer School in Physics 2005 on High Energy Laser-Matter Interactions,” D. Jaroszynsky, ed., (CRC Press, Taylor and Francis Group, 2007)

[5] D. A. Callahan and M. Tabak, Phys. Plasmas 7, 2083 (2000)

[6] H. Nishimura, T. Endo, H. Shiraga, Y. Kato, and S. Nakai, Appl. Phys. Lett. 62, 12 (1993)

[7] T. J. Orzechowski, M. D. Rosen, H. N. Kornblum, J. L. Porter, L. J. Suter, A. R. Thiessen, and R. J. Wallace, Phys. Rev. Lett. 77, 3345 (1996)

[8] D. Colombant, M. Klapisch, and A. Bar-Shalom, Phys. Rev. E. 57, 3411 (1998)

[9] A. Bar-Shalom, J. Oreg, W. H. Goldstein, D. Shvarts, and A. Zigler, Phys. Rev. A 40, 3183 (1989)

[10] L. Suter, J. Rothenberg, D. Munro, B. Van Wonterghem, and S. Haan, Phys Plasmas 7, $2092(2000)$

[11] G. B. Zimmerman and W. L. Kruer, Comm. Plasma Phys. Contr. Fusion 2, 51 (1975)

[12] D. A. Callahan, et al., Phys. Plasmas 13, 056307 (2006) 
[13] D. E. Post, R. V. Jensen, C. B. Tarter, W. H. Grasberger, and W. A. Locke, Atomic Data and Nucl. Data Tables 20, 397 (1977)

[14] J. M. Soures, et al. Phys. Plasmas 3 (5), 2108 (1996).

[15] L. Suter, Lawrence Livermore National Laboratory, private communication

[16] H. N. Kornblum, R. L. Kauffman, and J. A. Smith, Rev. Sci Inst. 57 (1986)

[17] R. E. Olson, R. J. Leeper, S. C. Dropinski, L. P. Mix, G. A. Rochau, S. H. Glenzer, O. S. Jones, L. J. Suter, J. L. Kaae, C. H. Shearer, and J. N. Smith, Rev. Sci. Instr. 74, 2186 (2003)

[18] R. E. Olson, Sandia National Laboratory, private communication

[19] J. Kaae and A. Nikroo, General Atomics, private communication

[20] G. Rochau and R. E. Olson, Sandia National Laboratory, private communication

Figure Captions:

Figure 1: Schematic of a laser-heated hohlraum showing the balance between x-ray sources and sinks.

Figure 2: Schematic of a radiation-driven nonlinear heat wave (Marshak wave) propagating into a cold slab of material.

Figure 3: The cold opacity of $\mathrm{Au}$ and $\mathrm{Gd}$ as a function of photon energy illustrating how in cocktail mixtures the materials fill in each others opacity gaps, resulting higher opacity than either single material.

Figure 4: Plot of the ratio of the radiation wall loss for U-Au and U-Au-Dy mixtures relative to pure $\mathrm{Au}$ as a function of fraction of $\mathrm{Au}$. This is for a NIF-like radiation drive with a $300 \mathrm{eV}$ peak drive temperature. 
Figure 5: Plot of the Rosseland mean opacity as a function of temperature for Au and the $\mathrm{U}: A u: D y$ cocktail mixture.

Figure 6: Radiation drive temperature (left) and radiation wall loss ratio (cocktail to gold) as a function of time for $300 \mathrm{eV}$ NIF ignition design.

Figure 7: Comparison of distribution of radiation energy in terms of wall loss, LEH loss, and capsule absorbed energy for gold and cocktail hohlraums with same radiation drive.

Figure 8: Results of $\mathrm{Au} / \mathrm{Gd}$ cocktail side-by-side burn-through experiment [7] showing delayed burn-through of cocktail foil.

Figure 9: Experimental setup for side-by-side re-emission experiment for U:Au:Dy:Ta cocktails compared to gold.

Figure 10: Filter transmission for the $450 \mathrm{eV}$ channel.

Figure 11: Experimental data for U:Au:Dy:Ta cocktail split-plate re-emission at $100 \mathrm{eV}$.

Figure 12: Ratio of U:Au:Dy:Ta cocktail re-emission to gold for photon frequencies filtered by broadband filter centered near $450 \mathrm{eV}$.

Figure 13: Schematic of experiment setup for gold and U:Au:Dy cocktail hohlraum experiments on Omega. Also shown are four typical 1-ns square laser pulses (each color is a different pulse from the same day of experiments - these are from the May 2005 experiments).

Figure 14: Snapshot at $1 \mathrm{~ns}$ from Lasnex calculation of $270 \mathrm{eV}$ U:Au:Dy cocktail hohlraum. Only the 42-degree beam cone is shown.

Figure 15: Measured Dante flux from first U:Au:Dy:Ta cocktail hohlraum experiment showing two gold hohlraums (red solid curves) and three cocktail hohlraums (blue dashed curves). 
Figure 16: Measured $\Delta \mathrm{T}_{\mathrm{r}}$ from several Omega experiments with $270 \mathrm{eV}$ hohlraums at time of peak drive compared with model predictions assuming no oxygen in the cocktail (black bars) and $42 \%$ oxygen (green bars).

Figure 17: Illustration of the new technique for making cocktail hohlraums in which material sputtered onto inside of split gold hohlraum (a), which was then joined (b).

Figure 18: Data from Auger measurement of the atomic fraction of constituents as a function of depth into the material for a cocktail witness plate.

Figure 19: Spectrally-integrated flux versus time for two sequential experiments for gold (red) and cocktail (blue).

Figure 20: Fit Dante spectra at 1 ns for gold (red) and cocktail (blue).

Figure 21: Comparison of the calculated and measured Dante channel ratios (cocktail/gold).

Figure 22: $\Delta \mathrm{T}_{\mathrm{r}}$ versus time for two sequential shots and compared with 2D Lasnex (blue) and simple energy balance model (red).

Figure 23: Summary of the data in terms of $\Delta T_{r}$ at time of peak drive for all hohlraum temperatures tested.

Figure 24: Photo of a prototype NIF-scale $\mathrm{U}_{.75} \mathrm{Au}_{.25}$ multilayer cocktail half hohlraum. 


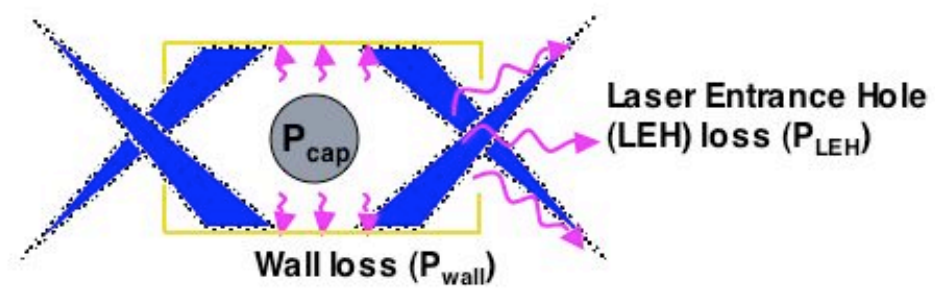

Figure 1 

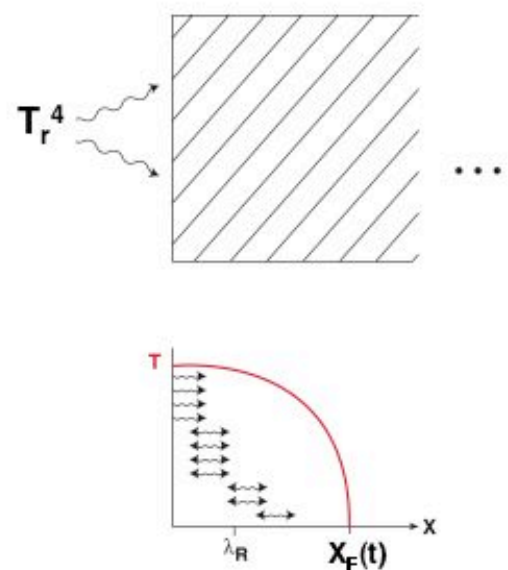

Figure 2 


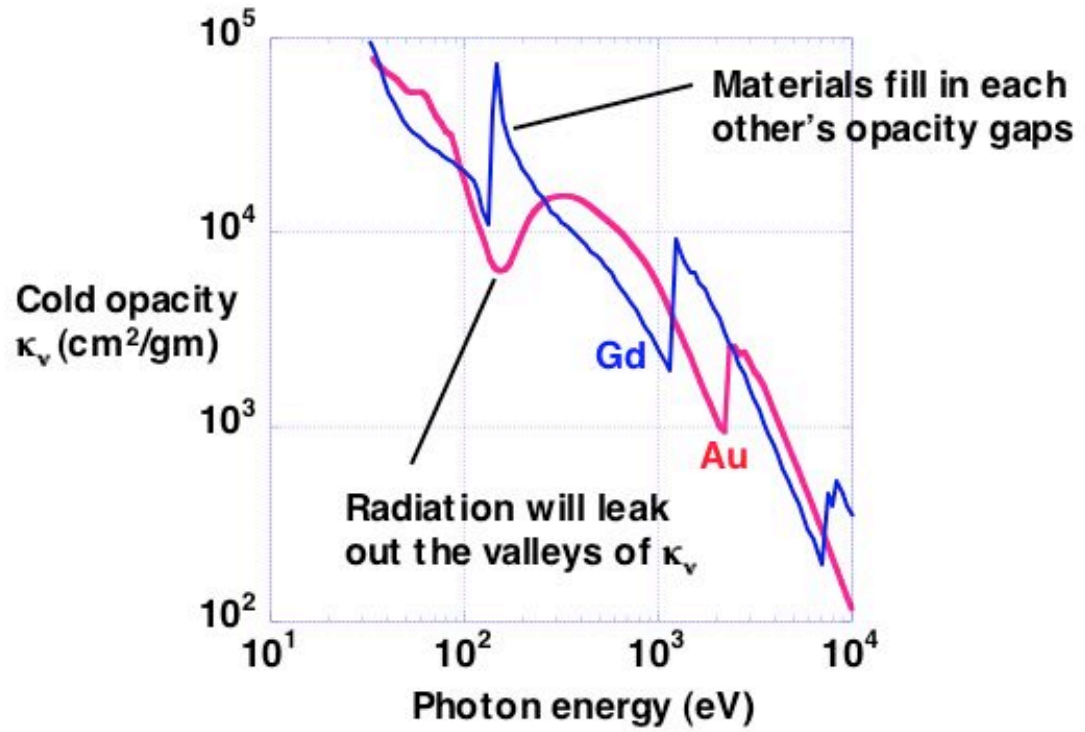

Figure 3 


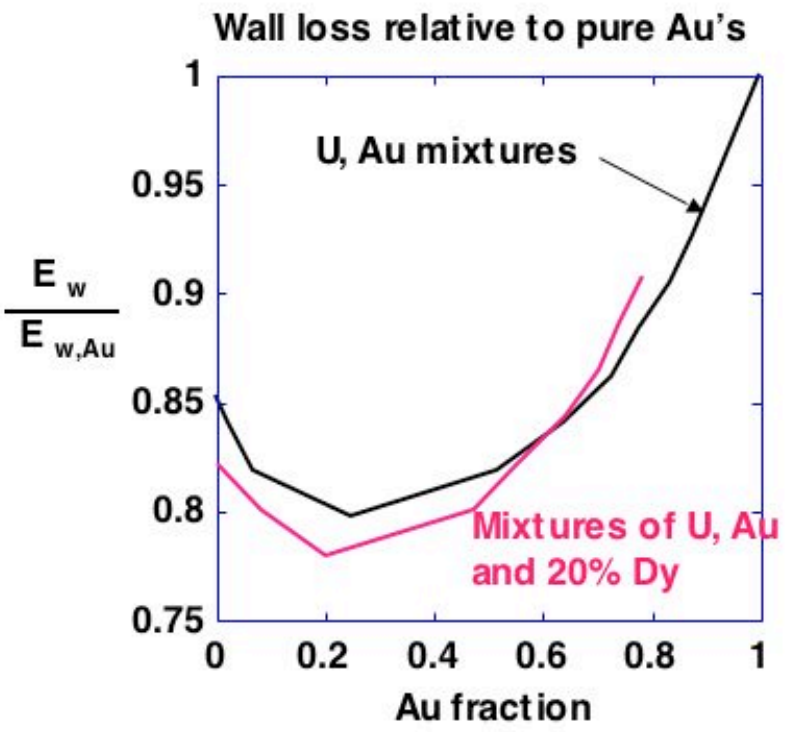

Figure 4 


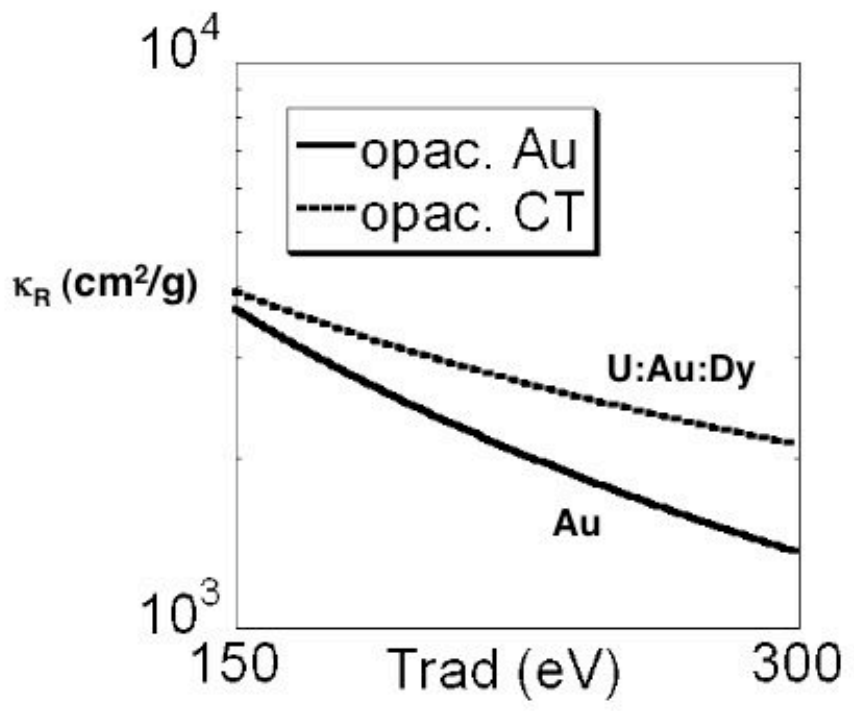

Figure 5 


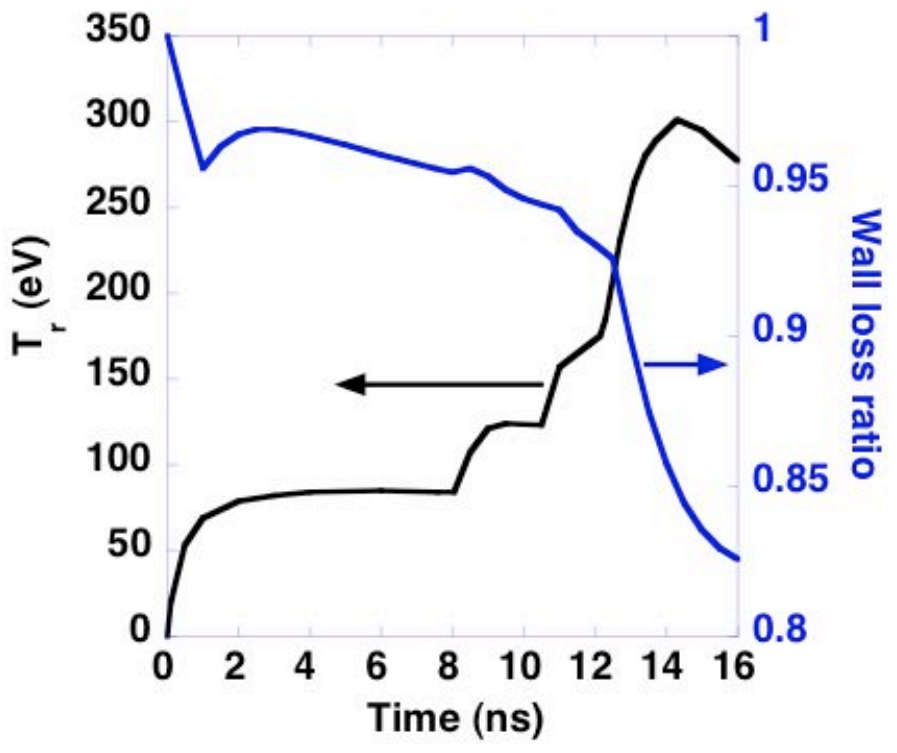

Figure 6 


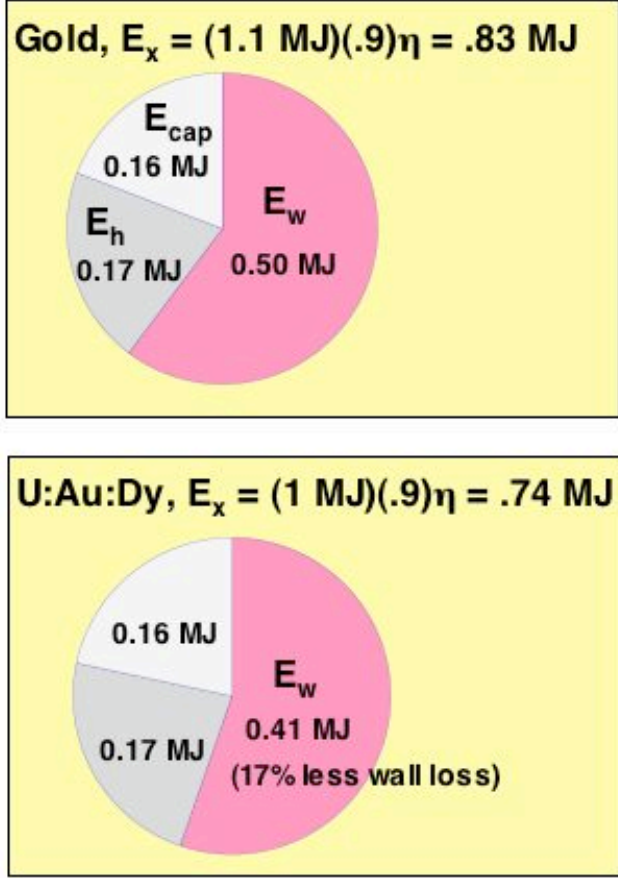

Figure 7 


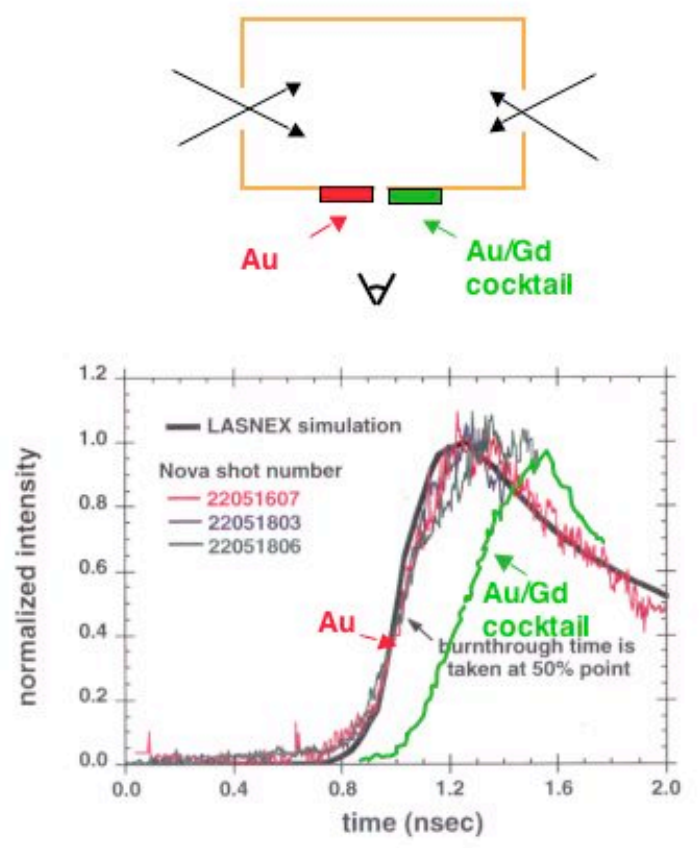

Figure 8 

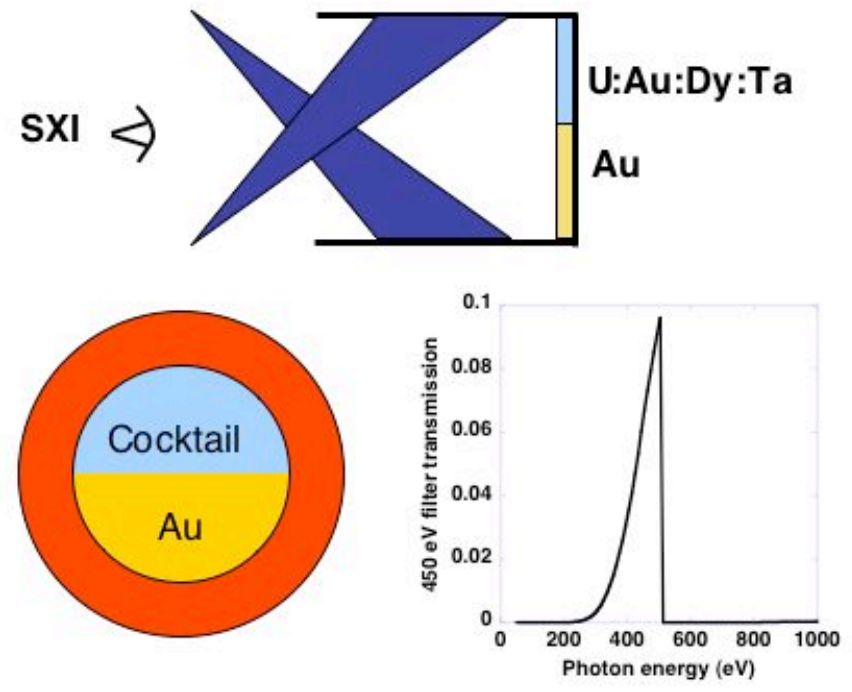

Figure 9 

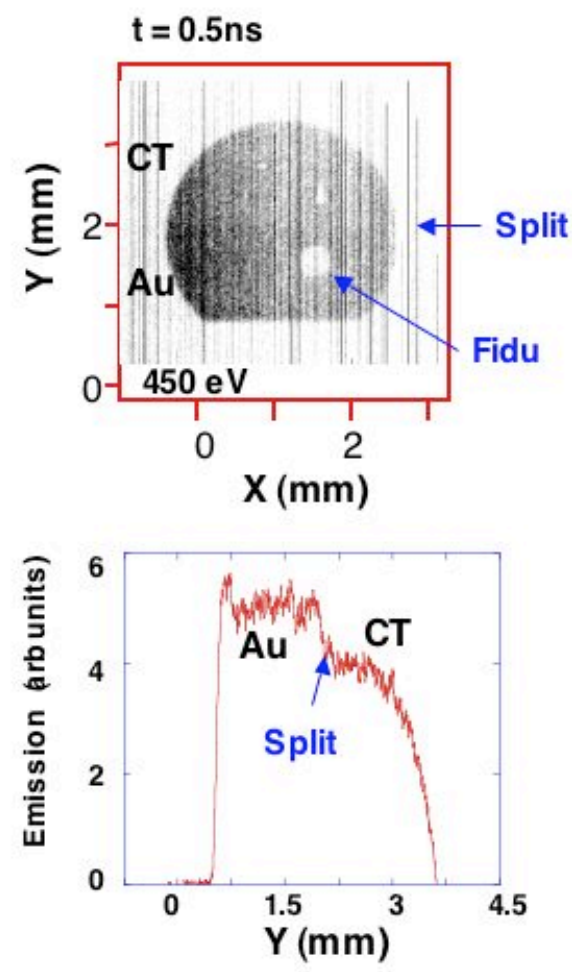

Figure 10 

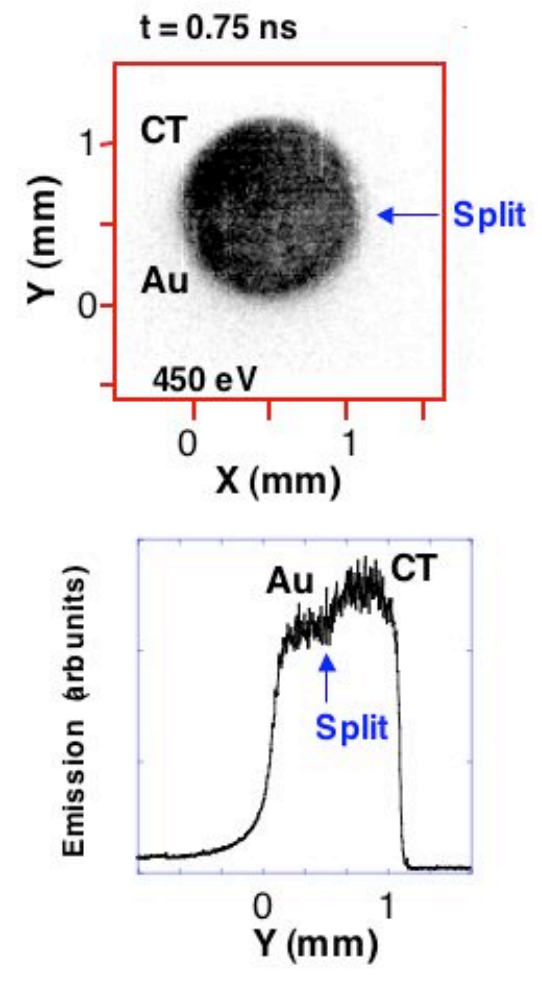

Figure 11 


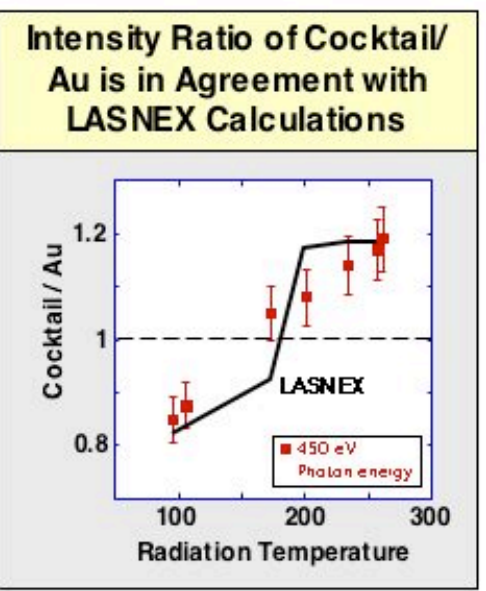

Figure 12 

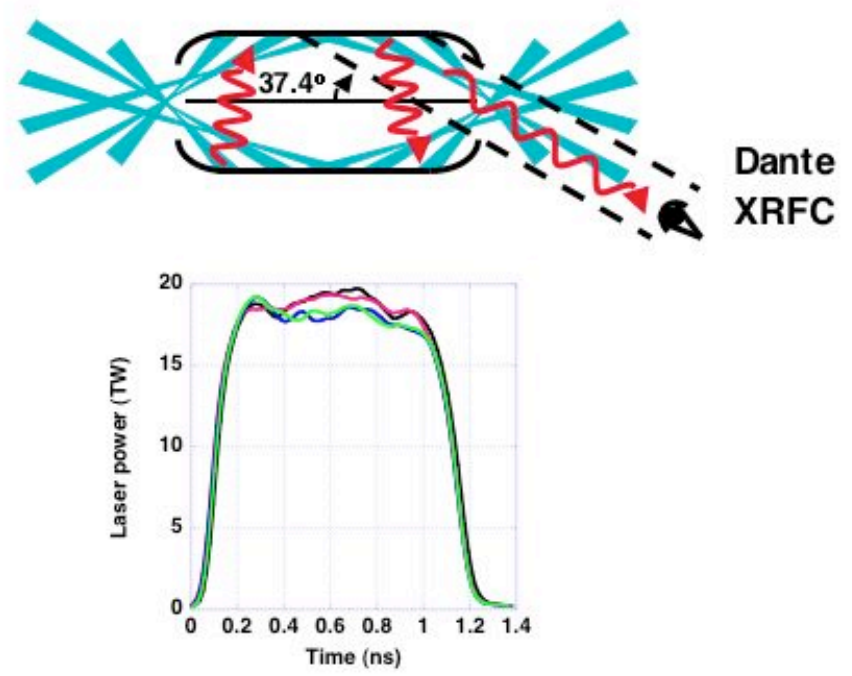

Figure 13 


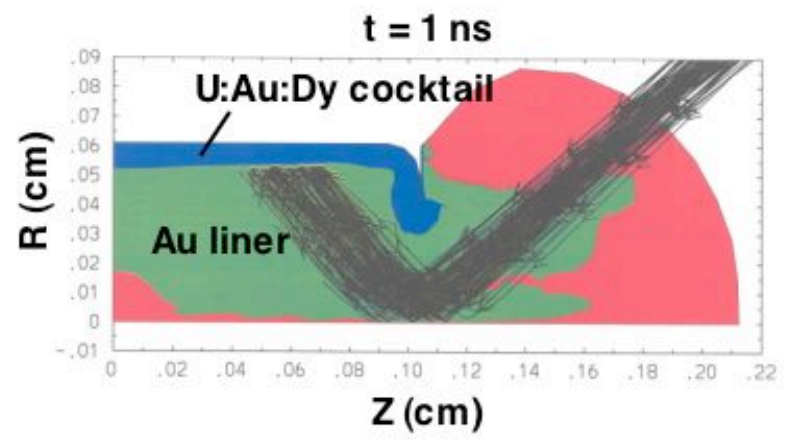

Figure 14 


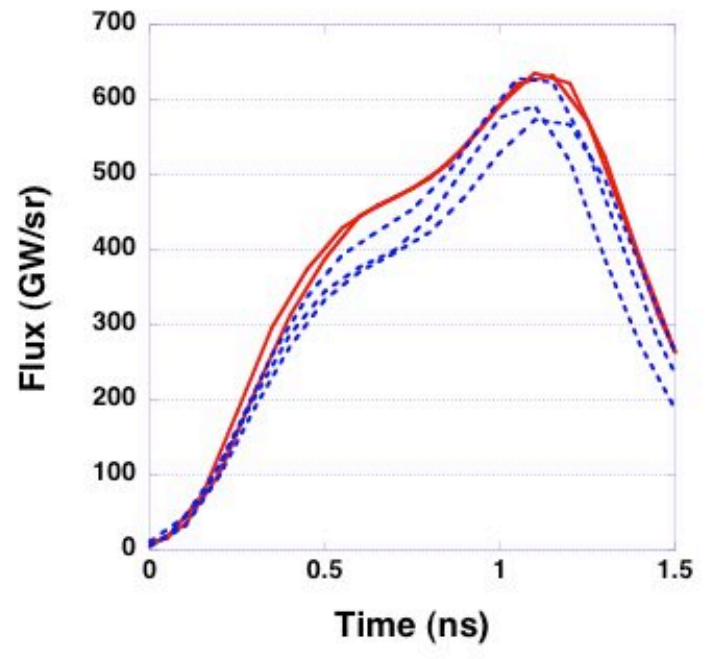

Figure 15 


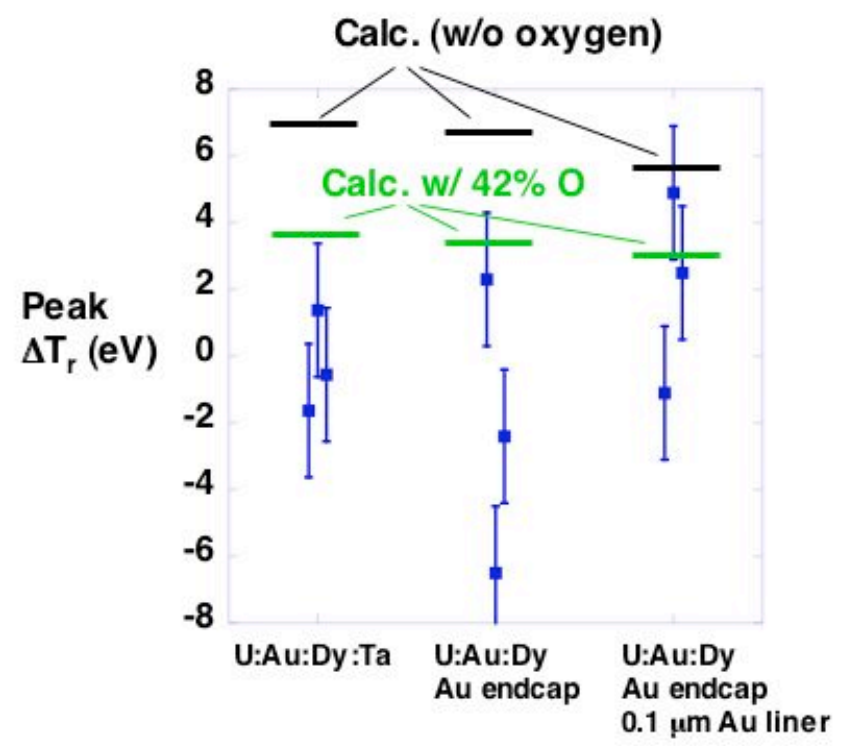

Figure 16 


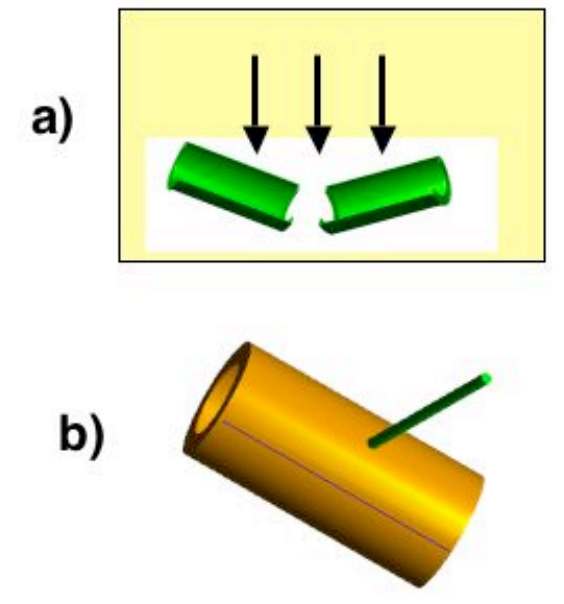

Figure 17 


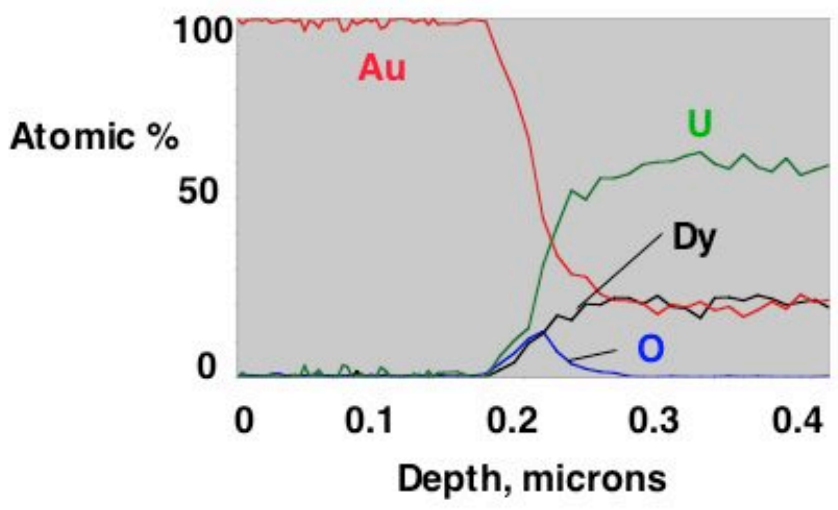

Figure 18 


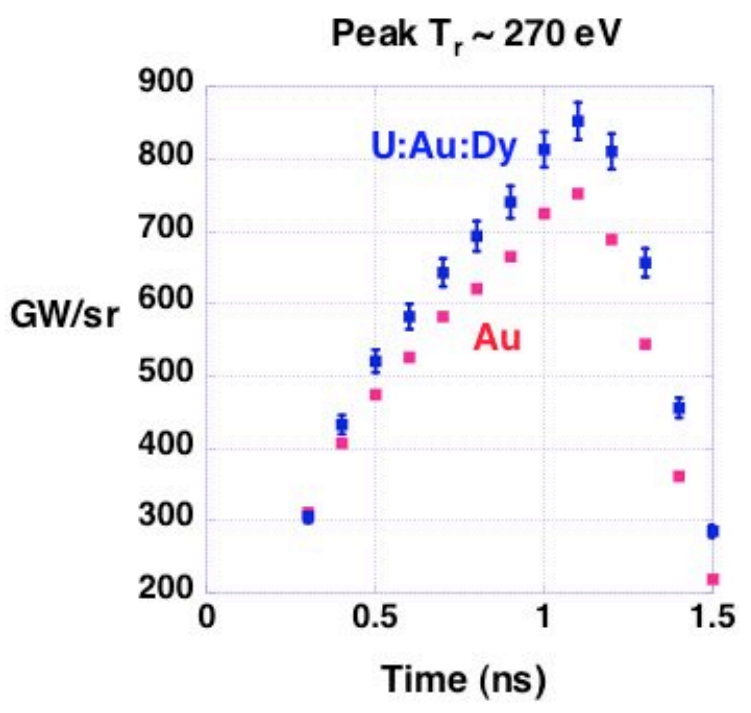

Figure 19 


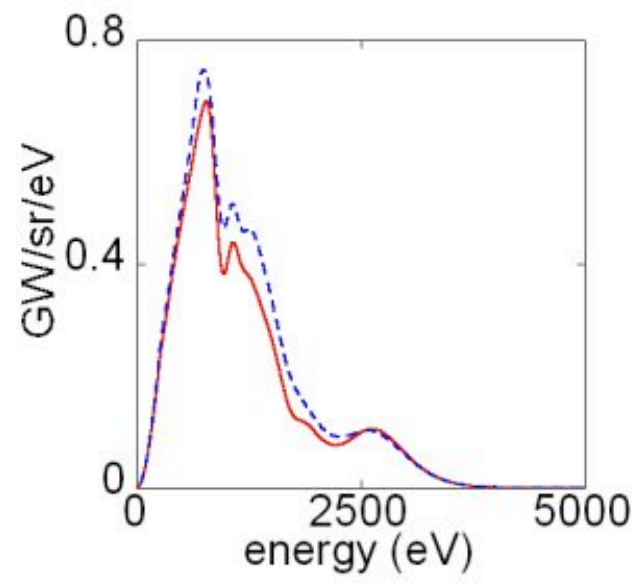

Figure 20 


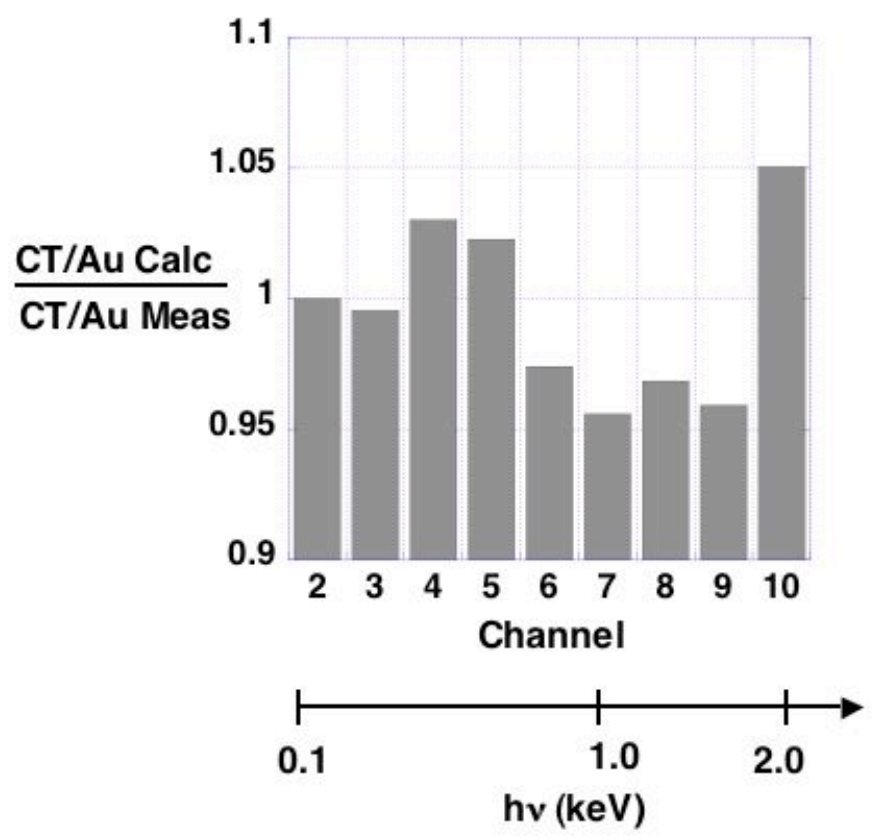

Figure 21 


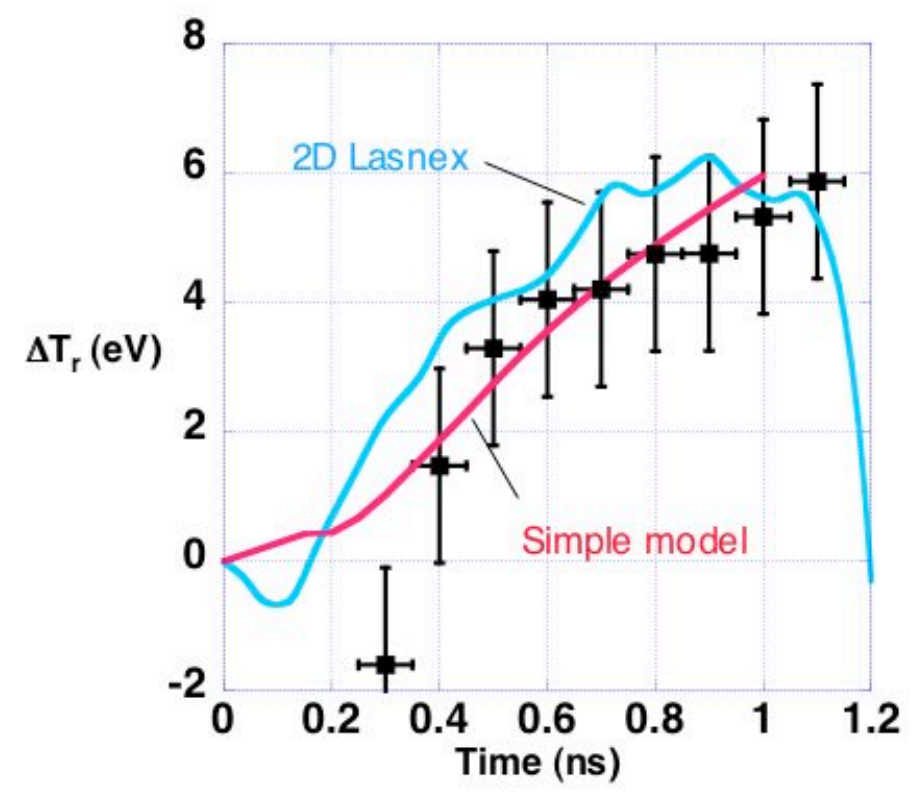

Figure 22 


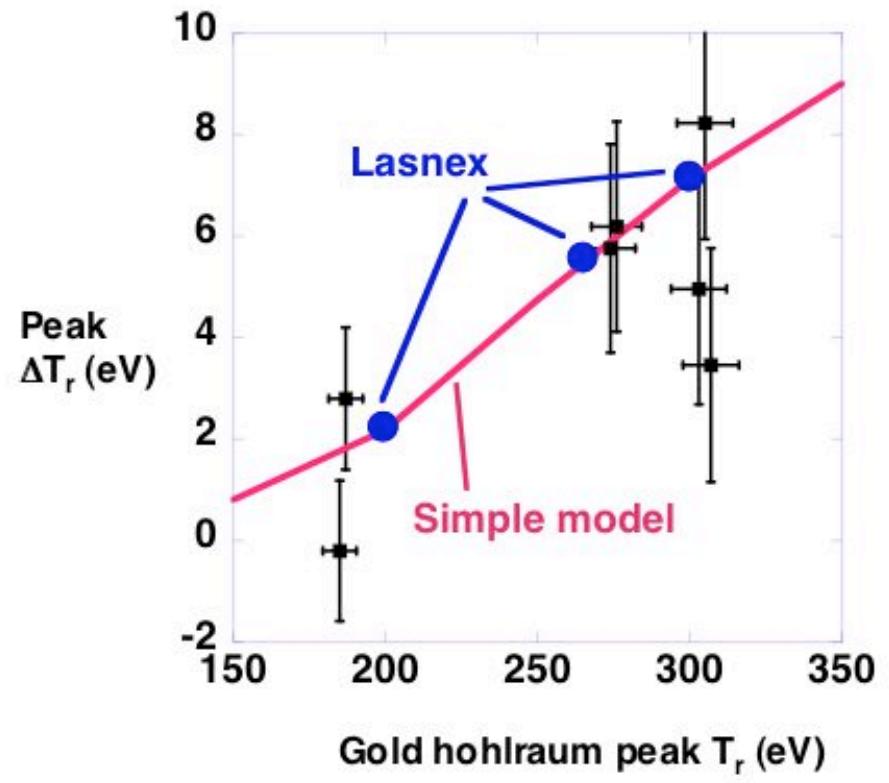

Figure 23 


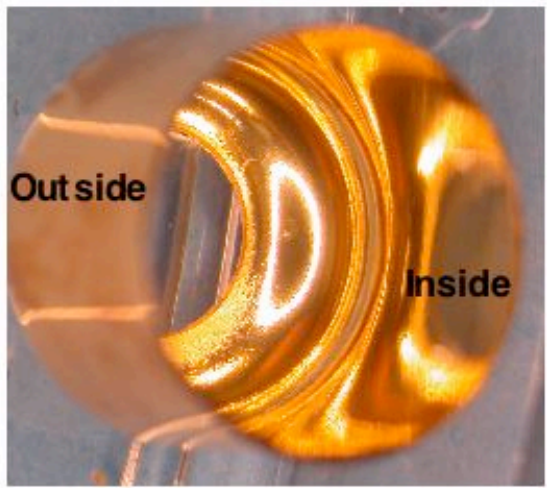

$5.1 \mathrm{~mm}$ diameter, $7 \mu \mathrm{m}$ cockt ail layer

Figure 24 